\section{REFERENCES}

1. Ward HP, Block MH. The natural history of agnogenic myeloid metaplasia and a critical evaluation of its relationship with the myelodysplastic syndrome. Medicine 1971;50:357-420.

2. Shih LY, Lin FC, Kuo TT. Cutaneous and pericardial extramedullary hematopoiesis with cardiac tamponade in chronic myeloid leukemia. Am J Clin Pathol 1988; 89:693-7.

3. Lewis TN, Klingerman MM. Pericardial and myocardial involvement by leukemias and lymphomas. Cancer 1970;25:1004-8.

4. Vilaseca J, Arnau JM, Tallada N, Bernardo L, Lopez-
Vivancos J, Guardia J. Agnogenic myeloid metaplasia presenting as massive pericardial effusion due to extramedullary hematopoiesis. Acta Haematol 1985;73: 239-40.

5. Pipoly GM, Rogers J. Cardiac tamponade resulting from pericardial extramedullary hematopoiesis. Cancer 1979;44:1504-6.

6. Bubley G, Come P, MacDougall D, Thurer R, Goldberg J. Pericardial tamponade associated with myeloid metaplasia. Am J Hematol 1983;14:185-8.

7. Haedersdal C, Hasselbalch H, Devantier A, Sounamaki K. Pericardial hematopoiesis with tamponade in myelofibrosis. Scand J Haematol 1985;34:270-3.

\title{
PRIMARY AORTIC SARCOMA: RESECTION BY TOTAL ARCH REPLACEMENT
}

Satoshi Sekine, MD, Tadaaki Abe, MD, Keiji Seki, MD, Yoshiki Shibata, MD, and Itsuro Yamagishi, MD, Akita, Japan

Because of the rarity and varying presentations of primary aortic tumors, antemortem diagnosis of these tumors is difficult. This report presents the case of a patient with primary aortic malignant hemangioendothelioma involving the aortic arch, which was resected with total arch replacement.

A 53-year-old woman was readmitted to Akita University Hospital with frequent recurrence of a low-grade fever. She had been well 6 months earlier after admission to this hospital with progressive general fatigue and a low-grade fever. During the first admission, no malignant disease was detected, and all tumor markers were within normal limits. A diagnosis of sacroiliac arthritis was made, and she was discharged home receiving a low dose of prednisolone ( $5 \mathrm{mg} /$ day) and loxoprofen (180 mg/day).

On physical examination at readmission to the hospital, she was pale and a systolic grade 2 murmur was noticed along the upper right sternal border and the neck. No other pathologic conditions were revealed. Laboratory examination showed the following values: hemoglobin 7.2 $\mathrm{gm} / \mathrm{dl}$, hematocrit $23.7 \%$, white blood cell count $16.9 \times$ $10^{3} / \mu \mathrm{l}$, erythrocyte sedimentation rate $165 \mathrm{~mm} / \mathrm{hr}$, and C-reactive protein $11.2 \mathrm{mg} / \mathrm{dl}$. Four days later, she had sudden cyanosis and numbness of the toes. The dorsal pedal pulses were present, and the ischemia improved within a day. Electrocardiography showed normal sinus rhythm and echocardiography showed no abnormalities in the heart. The aortitis syndrome was suspected and computed tomographic scanning of the chest was done, which

From the Department of Cardiovascular Surgery, Akita University School of Medicine, Akita 010, Japan.

J ThoraC CARDIOvasc Surg 1995;110:554-6

Copyright (C) 1995 by Mosby-Year Book, Inc.

$0022-5223 / 95 \$ 3.00+0 \quad \mathbf{1 2 / 5 4 / 6 1 7 1 4}$

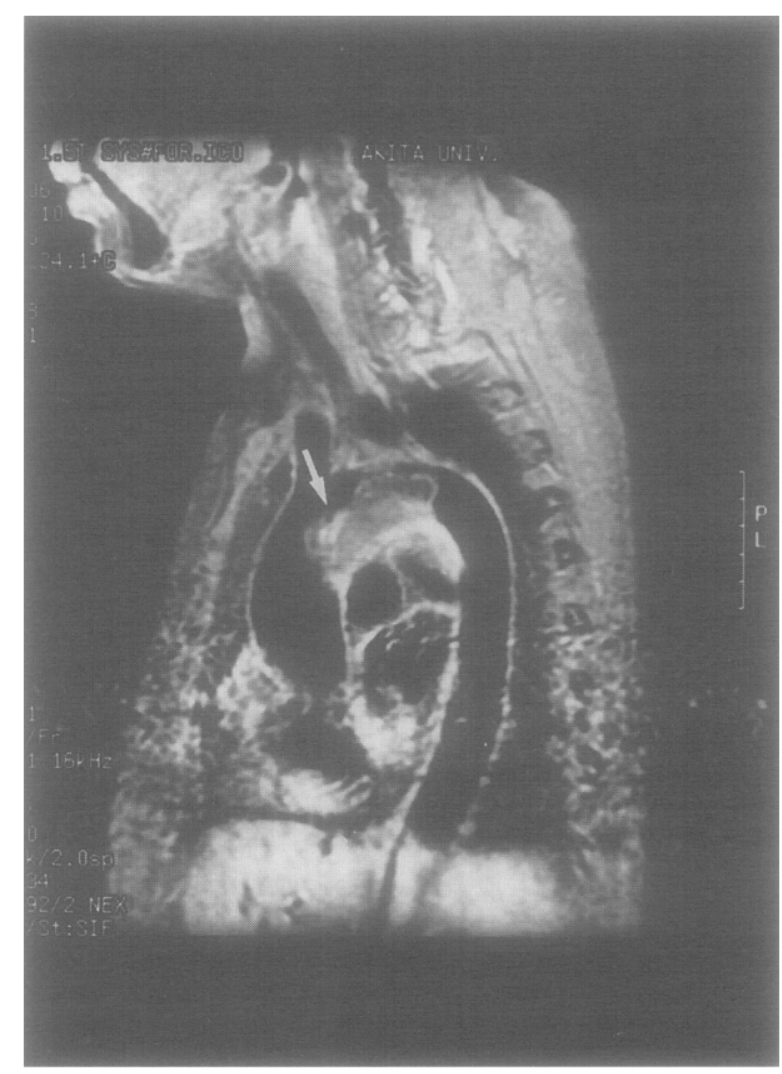

Fig. 1. MRI of chest demonstrates that tumor (arrow) arising from inferior surface of aortic arch occupies practically entire transverse aorta and part of ascending and descending arch of aorta. 

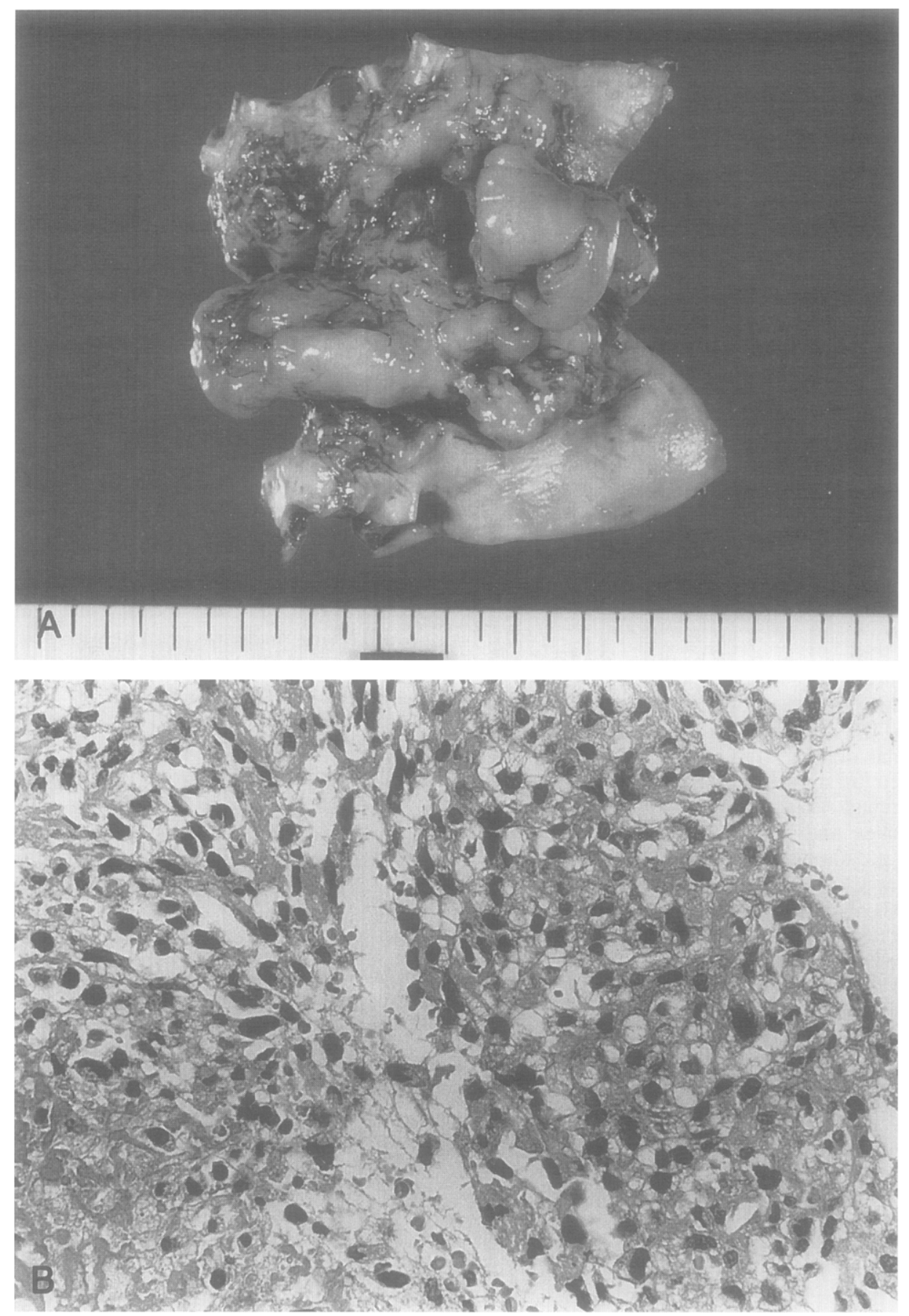

Fig. 2. A, Resected aortic arch with tumor. B, Histologic section of tumor (hematoxylin and eosin stain, original magnification $\times 500$ ).

disclosed an obstruction in the aortic arch. Magnetic resonance imaging (MRI) of the chest, with sagittal and coronal projections, demonstrated intraluminal tumor in the aortic arch (Fig. 1). No intracardiac abnormality was noticed. Thus the diagnosis of primary intraaortic arch tumor was established. There was no evidence of tumor in the lungs or other organs. Because of the obstruction of the aortic flow and the suspected episode of distal embolization, emergency operation was indicated.

While the patient was being prepared for operation, a pressure gradient of $30 \mathrm{~mm} \mathrm{Hg}$ between the upper and lower extremities was observed. At operation, the aortic 


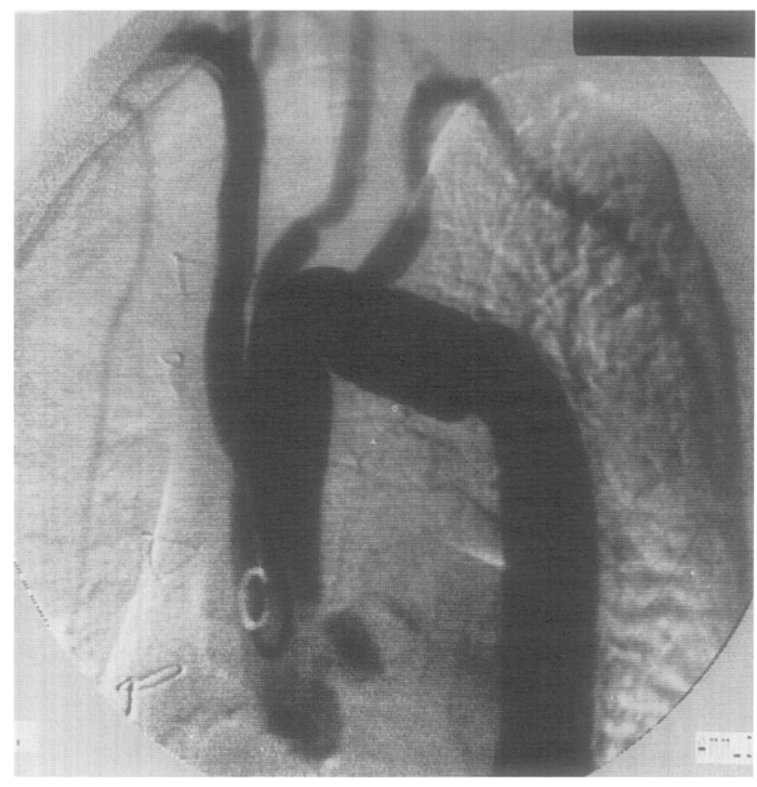

Fig. 3. Aortogram 1 month after operation.

arch and its branches were exposed by median sternotomy and left collar incision. There was no evidence of tumor invasion beyond the aorta and no pathologic changes of other mediastinal organs were noticed. The aorta was resected between just above the coronary sinuses and the proximal descending aorta with the proximal portions of the arch branches and was reconstructed with three small-diameter prostheses attached to a $24 \mathrm{~mm}$ Hemashield graft (Meadox Medicals Inc., Oakland, N.J.).

The tumor was a whitish, irregular elevated lesion, 5.5 $\times 5.5 \times 1.0 \mathrm{~cm}$ in size, and it originated from the intima of the inferior wall of the aortic arch (Fig. 2, $A$ ). Histologic examination revealed the tumor to be malignant hemangioendothelioma. The tumor was composed of primitive and bizarre hyperchromatic cells with high cellularity and frequent mitoses (Fig. 2, B). No tumor cells were found at either end of the resected aorta. The postoperative course was uneventful. An aortogram done 1 month after the operation demonstrated satisfactory reconstruction of the thoracic aorta (Fig. 3). The patient has been well for 2 months since the operation.

Primary intraluminal aortic tumors are rare and only 37 cases were reported by 1993. Because of a lack of typical presentations and their rarity, antemortem diagnosis is difficult, and only a few cases were reported in which the tumors were resected. ${ }^{1-3}$ In cases with vascular bruit and an episode of distal embolization without heart disease, primary aortic tumors are considered as possible causes of embolic events. ${ }^{4-6}$ Although resection of the tumor is noncurative in most cases because the initial symptoms usually represent an advanced stage, ${ }^{3}$ surgical resection of the tumors is warranted for the relief of the aortic obstruction and distal tumor embolization. For preoperative evaluation, we found MRI to be the superior aid in diagnosis of invasion and extension of aortic tumors in comparison with conventional aortogram, which may cause serious complications such as distal tumor embolization.

\section{REFERENCES}

1. Kattus AA Jr., Longmire WP, Cannon JA, Webb R, Johnston C. Primary intraluminal tumor of the aorta producing malignant hypertension: successful surgical removal. N Engl J Med 1960;262:694-700.

2. Millili JJ, Laflare RG, Nemir P Jr. Leiomyosarcoma of the abdominal aorta: a case report. Surgery 1981;89: 631-4.

3. Crawford ES, Crawford JL. Aortic tumors. In: Crawford ES, Crawford JL, eds. Diseases of the aorta. Baltimore: Williams and Wilkins, 1984:378-93.

4. Winkelmann RK, Van Heeden JA, Bernatz PE. Malignant vascular endothelial tumor with distal embolization: a new entity. Am J Med 1971;51:692-7.

5. Mason MS, Wheeler JR, Gregory RT, Gayle RG. Primary tumors of the aorta: report of a case and review of the literature. Oncology 1982;39:167-72.

6. Higgins R, Posner MC, Moosa HH, Stanley C, Pataki $\mathrm{KI}$, Mendelow H. Mesenteric infarction secondary to tumor emboli from primary aortic sarcoma. Cancer 1991;68:1622-7. 